ROCZNIKI KULTUROZNAWCZE

Tom XI, numer $2 \quad-\quad 2020$

DOI: http://dx.doi.org/10.18290/rkult20112-6

\author{
ANNA MAGDALENA KOSIŃSKA \\ MICHAŁ BEER
}

\title{
ZJAWISKO „MAKDONALDYZACJI” KULTURY W ORZECZNICTWIE TRYBUNAŁU SPRAWIEDLIWOŚCI UNII EUROPEJSKIEJ
}

\section{UWAGI WSTĘPNE}

Współczesna kultura to niejednorodna struktura, stanowiąca mozaikę kultur lokalnych i kultury globalnej. Dychotomia nowoczesnej kultury przejawia się również $\mathrm{w}$ kontrastach $\mathrm{w}$ obszarze dostępnej oferty kulturalnej — z jednej strony odbiorcy i uczestnicy życia kulturalnego mają możliwość korzystania z kultury wysokiej, czego przykład może stanowić malarstwo dostępne $\mathrm{w}$ muzeach i galeriach sztuki, $\mathrm{z}$ drugiej zaś strony rośnie rola przemysłu kreatywnego i kultury popularnej. O ile dobra kultury $\mathrm{w}$ klasycznym ich rozumieniu podlegają ochronie prawnej poprzez dostępne instrumenty prawne w systemie prawa krajowego i prawa międzynarodowego ${ }^{1}$, o tyle niejasny pozostaje status dóbr kultury masowej.

Autorzy artykułu stawiają tezę, że popkultura ze względu na swoją efemeryczność ${ }^{2}$ zasługuje na ochronę prawną i ta ochrona jest realna. Materiałem analizowanym w artykule jest orzecznictwo Trybunału Sprawiedli-

Dr hab. Anna Magdalena KosińsKa, prof. KUL — Katolicki Uniwersytet Lubelski Jana Pawła II, Wydział Prawa i Administracji, Katedra Prawa Międzynarodowego i Prawa Unii Europejskiej; adres do korespondencji - e-mail: kosiania@kul.pl. ORCID: https://orcid.org/0000-0002-0915$874 \mathrm{X}$.

Mgr Michą BeER - doktorant WPiA KUL; adres do korespondencji - e-mail: mbeer@ student.kul.lublin.pl. ORCID: https://orcid.org/0000-0001-7187-423X.

${ }^{1}$ Zob. artykuły 5,6 i 73 Konstytucji RP (Konstytucja Rzeczypospolitej Polskiej z dnia 2 kwietnia 1997 r., Dz.U. 1997 Nr 78 poz. 483), art. 15 Międzynarodowego Paktu Praw Gospodarczych, Społecznych i Kulturalnych otwartego do podpisu w Nowym Jorku dnia 19 grudnia 1966 r., Dz. U. z 1977 r. Nr 38 poz. 169.

${ }^{2}$ Władysław Kopalı́́ski, Stownik mitów i tradycji kultury (Warszawa: PIW, 1987), 910. 
wości Unii Europejskiej dotyczące ikon szeroko rozumianej kultury popularnej, takich jak Coca-Cola, McDonald's, kostka Rubika i LEGO. Słuszne wydaje się twierdzenie, że „orzecznictwo dotyczące ikon popkultury jest z jednej strony dowodem na pogłębiającą się globalizację i 'makdonaldyzację’ świata, z drugiej zaś na sprzężenie kultury z sektorem kreatywnym”’.

\section{POJĘCIE POPKULTURY I JEJ ATRYBUTY}

Popkultura, kultura masowa czy wreszcie przemysł kultury to synonimy trudnego do uchwycenia zjawiska, którego genezy należy upatrywać w pojawieniu się społeczeństw zindustrializowanych i zurbanizowanych ${ }^{4}$. Za symboliczny początek przyjmuje się pierwszą połowę XIX wieku i upowszechnienie drukarskiej prasy mechanicznej oraz drukarskiej maszyny rotacyjnej ${ }^{5}$. Władysław Kopaliński w swoim Słowniku mitów i tradycji kultury definiuje popkulturę jako

[...] wynik wpływu życia miejskiego (produkcji masowej, obfitości pieniędzy na wydatki osobiste i ogólnego buntu przeciw miernikom ludzi starszych) na młodsze pokolenie: kultura, którą cechuje efemeryczność [...], życie chwilą obecną, strach przed posądzeniem o przestarzałe gusta, płytki stosunek do problemów oraz brak świadomości klasowej i rasowej ${ }^{6}$.

W podejściu do problematyki popkultury przeważa ocena krytyczna. Popkulturę uważa się za leżącą na przeciwnym biegunie od tzw. kultury wysokiej, za zagrożenie dla niej, zagrożenie dla kultury w ogóle, a nawet za świadectwo jej upadku? ${ }^{7}$ Przypisuje się jej wiele negatywnych cech, hołdowanie niewyszukanym gustom, epatowanie szokującymi treściami w celu przyciągnięcia jak najszerszego grona odbiorców. Postulat podejścia neutralnego do kultury masowej pojawia się u Antoniny Kłoskowskiej, która proponuje, aby definicje tego zjawiska były pozbawione elementu oceniającego, dzięki czemu będą mogły objąć większą liczbę zjawisk kulturalnych ${ }^{8}$. O zanikaniu podziału na wartości kulturowe wyższe i niższe w następstwie

\footnotetext{
${ }^{3}$ Anna Magdalena Kosińska, Prawa kulturalne obywateli państw trzecich $w$ prawie Unii Europejskiej (Lublin: Wydawnictwo KUL, 2018), 182.

${ }^{4}$ Antonina KŁoskowsKa, Kultura masowa (Warszawa: Wydawnictwo Naukowe PWN, 2005). s. 101 .

${ }^{5}$ Andrzej Kaliszewski, Gtówne nurty w kulturze XX i XXI wieku (Warszawa: Poltext, 2012), 133.

${ }^{6}$ Kopalı́́sKI. Stownik mitów i tradycji kultury, 910.

${ }^{7}$ Anna Magdalena KosińSKA, Kulturalne prawa człowieka (Lublin: Wydawnictwo KUL, 2014), 32.

${ }^{8}$ KŁoskowsKa, Kultura masowa, 95.
} 
postępujących zmian społecznych i infrastrukturalnych pisze Zygmunt Bauman'.

W przypadku kultury wysokiej możemy mówić o jej twórcach jako autorytetach, jej zaś wytworami są dzieła. Dziełami, a pozostając w nomenklaturze przemysłu kultury - produktami popkultury, są jej ikony. Ikoną popkultury może stać się praktycznie wszystko i każdy. Zdarza się, że ikoną popkultury zostaje twórca kultury wysokiej. Tak jest w przypadku amerykańskiego artysty Andy'ego Warhola. Ikonami popkultury stały się także jego poszczególne dzieła. Do powszechnej świadomości odbiorców weszły obrazy przedstawiające puszki zupy pomidorowej Campbell's, butelki CocaColi, a także zwielokrotnione w technologii sitodruku portrety Marylin Monroe. O ile samego Warhola, jako przedstawiciela pop-artu, można by zaliczyć do twórców działających na pograniczu kultury wysokiej i masowej, to wątpliwości nie powinno pozostawiać zaliczenie do tej pierwszej grupy Leonarda da Vinci. Ikoną popkultury stał się jego obraz Mona Lisa (La Gioconda). Powielana na kubkach, t-shirtach, wizytówka Luwru La Gioconda „wyszła z ram” i rozpoczęła niezależne życie ikony popkultury. Podobny los spotyka przedmioty codziennego użytku. Wspomniana przy okazji Warhola Coca-Cola jest dzisiaj chyba najbardziej ewidentnym przykładem działania mechanizmu popkulturowego. Sam Warhol pisał o niej tak: „To, co jest w tym kraju świetne, to fakt, że w Ameryce bogaci konsumenci kupują dokładnie to samo, co biedni. Każda Coca-Cola jest taka sama, każda jest tak samo dobra. Zna ją Liz Taylor, prezydent, włóczęga i ty sam"10. Ta wypowiedź idealnie ilustruje warunkujące proces powstawania kultury masowej, według Baumana, składniki procesu zaspokajania ludzkich potrzeb, tj. zależność od rynku, organizacji oraz od techniki ${ }^{11}$.

Obecnie kultura masowa wydaje się być samowystarczalna. Pożywką dla popkultury staje się kultura, a nawet sama popkultura. LEGO, kolejna z ikon popkultury, rozpoczyna sprzedaż klocków umożliwiających samodzielne budowanie obrazów przedstawiających postaci z serii Gwiezdne Wojny, zespół The Beatles czy po raz kolejny wspominaną Marylin Monroe Warhola ${ }^{12}$.

\footnotetext{
${ }^{9}$ Zygmunt Bauman, Szkice z teorii kultury (Warszawa: Wydawnictwo Naukowe Scholar, 2017), 366.

${ }^{10}$ Andy Warhol, The Philosophy of Andy Warhol: From A to B and Back Again (New York: Harcourt Brace Jovanovich, 1975), 100; „Andy Warhol i Coca-Cola. Od klasycznej do nowej Coca-Cola i z powrotem", COCA-COLA POLSKA, dostęp 13.07.2020, https://www.coca-cola.pl/bawsie-dobrze/ciekawostki/AndyWarholiCocaCola, .

${ }^{11}$ Bauman, Szkice z teorii kultury, 350-356.

${ }^{12}$ LEGO. Dostęp 15.07.2020. https://www.lego.com/pl-pl/themes/art. .
} 
Coca-Cola i Pepsi do swoich reklam zatrudniają znane postaci ze świata muzyki i sportu ${ }^{13}$.

Ramy popkultury są rozmyte, wpływa ona na kulturą lokalną, romansuje $\mathrm{z}$ wyższą. Tym samym trudne do zdefiniowania jest również pojęcie dóbr kultury masowej. Można jednak zaryzykować twierdzenie, że dobra kultury masowej stanowią dobra kultury ze względu na fakt, że kultura masowa stanowi twórczą działalność człowieka, jest efektem przekształcania natury i można ją traktować jako jeden z nurtów kultury rozumianej jako zjawisko uniwersalne. Konwertując definicję Dominika Strinatiego, dobra kultury masowej to efekt działań tworzonych przez technikę, przez masową technikę przemysłową i sprzedawanych dla zysku masowej publiczności konsumentów ${ }^{14}$.

Czy zatem dzieła i ikony popkultury stają się dobrami kultury i zasługują na ochronę prawną?

\section{ORZECZNICTWO TSUE DOTYCZĄCE IKON POPKULTURY}

Trybunał Sprawiedliwości Unii Europejskiej (TSUE) jest, zgodnie z art. 19 Traktatu o Unii Europejskiej (TUE), właściwy do orzekania „w zakresie skarg wniesionych przez państwa członkowskie, instytucje lub osoby fizyczne lub prawne; w trybie prejudycjalnym, na wniosek sądów państw członkowskich, w sprawie wykładni prawa Unii lub ważności aktów przyjętych przez instytucje; w innych sprawach przewidzianych w Traktatach"15. TSUE jako instytucja UE składa się z Trybunału Sprawiedliwości, Sądu oraz sądów wyspecjalizowanych.

Trybunał w swoim orzecznictwie skupiał się dotychczas na szeroko rozumianych kwestiach związanych z dobrami kultury, głównie poprzez orzecznictwo dotyczące swobody przepływu dóbr na rynku wewnętrznym ${ }^{16}$.

13 „'Mean' Joe Green Reflects on Iconic Coca-Cola Ad That Changed His Life: Commercial Appeal". 16.01.2014. The Coca-Cola Comapany. Dostęp 17.07.2020. https://www.coca-cola com pany.com/news/mean-joe-green-reflects-on-iconic-coke-ad; „Michael Jackson Pepsi Generation”. SME. Pepsi. Dostęp 17.07.2020. Youtube. https://youtube/po0jY4WvCIc.

${ }^{14}$ Zob. KaliszewsKi, Gtówne nurty w kulturze XX i XXI wieku, 133. Warto też zauważyć, że wytwory popkultury można uznać za dobra kultury w sytuacji, gdy przenoszą one „wartości” $\mathrm{z}$ obecnego pokolenia na przyszłe.

${ }^{15}$ Traktat o Unii Europejskiej, wersja skonsolidowana, Dz.U. UE C 202 z 7.06.2016, 13.

${ }^{16}$ Zob. np. Wyrok Trybunału Sprawiedliwości z 8.07.1999 r. w sprawie Teresa Fernández de Bobadilla przeciwko Museo Nacional del Prado, Comité de Empresa del Museo Nacional del Prado i Ministerio Fiscal, C 234/97, ECLI:EU:C:1999:367; Wyrok Trybunału Sprawiedliwości 
W ostatnich latach Trybunał orzekał również często w sprawach związanych np. $\mathrm{z}$ dostępem do książek ${ }^{17}$ czy też $\mathrm{w}$ kwestiach związanych $\mathrm{z}$ tożsamością kulturową $^{18}$. Wydaje się, że na podstawie dotychczas wypracowanej linii orzeczniczej Trybunału w sprawach dotyczących kwestii kulturowych można już mówić o ukształtowaniu się doktrynalnego acquis culturalis ${ }^{19}$.

Szczególny nurt orzeczniczy wśród acquis culturalis stanowią sprawy dotyczące tzw. ikon popkultury. W pierwszej kolejności warto wspomnieć o sprawie The Coca-Cola Company przeciwko Urzędowi Harmonizacji w ramach Rynku Wewnętrznego (dalej jako sprawa The Coca-Cola Company) ${ }^{20}$. Sprawa dotyczyła bezpośrednio rejestracji znaku towarowego. Te kwestie w prawie Unii Europejskiej regulowało Rozporządzenie 207/2009 w sprawie wspólnotowego znaku towarowego ${ }^{21}$, obecnie zastąpione przez rozporządzenie 2017/1001 $1^{22}$. Ówczesny Urząd Harmonizacji w ramach Rynku Wewnętrznego (OHIM), urząd właściwy do rejestracji znaków towarowych, został zastąpiony przez European Union Intellectual Property Office (EUIPO, Urząd Unii Europejskiej ds. Własności Intelektualnej) ${ }^{23}$. EUIPO funkcjonuje od 2016 r. na podstawie rozporządzenia $2017 / 1001^{24}$.

W sprawie The Coca-Cola Company producent coca-coli zaskarżył decyzję OHIM odmawiającą rejestracji jako znaku towarowego oznaczenia trój-

z 25.07.1991 r. w sprawie Stichting Collectieve Antennevoorziening Gouda i inni przeciwko Commissariaat voor de Media, C 288/89, ECLI:EU:C:1991:323; Wyrok Trybunału Sprawiedliwości z 16.01.2003 r. w sprawie Komisja Wspólnot Europejskich przeciwko Republice Włoskiej, C 388/01, ECLI:EU:C:2003:30.

${ }^{17}$ Zob. np. Wyrok Trybunału Sprawiedliwości z 30.04.2009 r. w sprawie Fachverband der Buch- und Medienwirtschaft przeciwko LIBRO Handelsgesellschaft mbH, C 531/07, ECLI: EU: C:2009:276; Wyrok Trybunału Sprawiedliwości z 10.11.2016 r. w sprawie Vereniging Openbare Bibliotheken przeciwko Stichting Leenrecht, C 174/15, ECLI:EU:C:2016:856.

${ }^{18}$ Wyrok Trybunału Sprawiedliwości z 22.12.2010 r. w sprawie Ilonka Sayn-Wittgenstein przeciwko Landeshauptmann von Wien, C 208/09, ECLI:EU:C:2010:806; Wyrok Trybunału Sprawiedliwości z 2.06.2016 r. w sprawie Nabiel Peter Bogendorff von Wolffersdorff przeciwko Standesamt der Stadt Karlsruhe i Zentraler Juristischer Dienst der Stadt Karlsruhe, C 438/14, ECLI:EU:C:2016:401

${ }^{19}$ KosińsKa, Prawa kulturalne obywateli państw trzecich, 172.

${ }^{20}$ Wyrok Sądu z dnia 24 lutego 2016 r. The Coca-Cola Company przeciwko Urzędowi Harmonizacji w ramach Rynku Wewnętrznego, T 411/14, ECLI:EU:T:2016:94.

${ }^{21}$ Rozporządzenie Rady (WE) nr 207/2009 z dnia 26 lutego 2009 r. w sprawie wspólnotowego znaku towarowego, Dz.U. UE L 78 z 24.3.2009, 1.

${ }^{22}$ Rozporządzenie Parlamentu Europejskiego i Rady (UE) 2017/1001 z dnia 14 czerwca 2017 r. w sprawie znaku towarowego Unii Europejskiej, Dz.U. UE L 154 z 16.6.2017, s. 1.

${ }^{23}$ EUIPO. The European Union Intellectual Property Office - Urząd Unii Europejskiej ds. Własności Intelektualnej, dostęp 13.07.2020, https://euipo.europa.eu/ohimportal/pl/the-office.

${ }^{24}$ Art. 2 rozporządzenia 2017/1001. 
wymiarowego tworzonego przez kształt butelki konturowej bez żłobień. Coca-cola jest marką rozpoznawalną na całym świecie, butelka zaś z napojem gazowanym stała się symbolem kultury konsumpcyjnej oraz aktywnego stylu życia ludzi młodych. Symbol coca-coli był również wykorzystywany przez artystów popkulturowych — warto tutaj wspomnieć chociażby o pracach Burtona Morrisa, który przedstawia butelkę coca-coli jako metaforę współczesnego stylu życia.

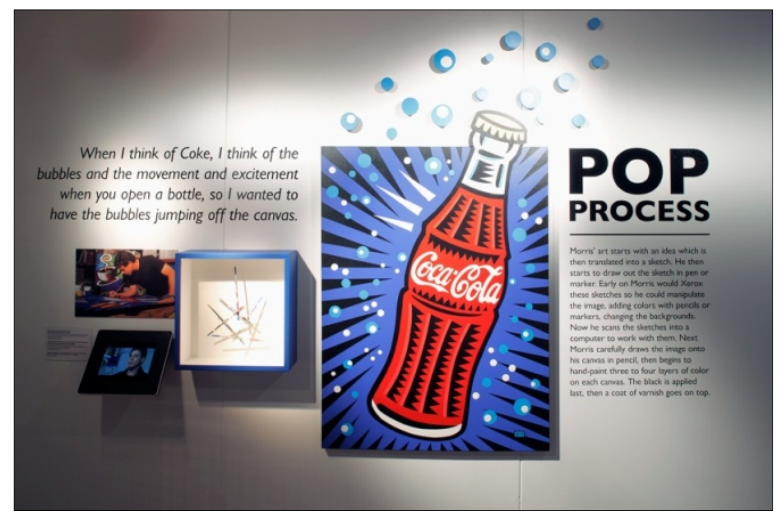

Praca Burtona Morrisa przedstawiająca butelkę coca-coli.

Źródło: https://burtonmorris.com/blog/gallery-view/exhibitions/, dostęp 13.07.2020.

W omawianej sprawie spółka Coca-Cola, mając już zarejestrowany słowny znak towarowy napoju, poszła o krok dalej, wnosząc o rejestrację przestrzennego kształtu butelki. Sprawa była o tyle ciekawa, że coca-cola w powszechnym odbiorze kojarzy się przede wszystkim jako napój sprzedawany w butelce konturowej ze żłobieniami. Coca-Cola chciała jako znak towarowy zarejestrować kolejny kształt butelki - tym razem bez żłobień. OHIM uznał, że zgłaszany znak towarowy jest pozbawiony charakteru odróżniającego ${ }^{25}$. Spółka Coca-Cola w postępowaniu przed OHIM twierdziła natomiast, że butelka bez żłobień będzie bez wątpienia kojarzona przez odbiorców produktu ze „sławną emblematyczną butelką ze żłobieniami",26, ponieważ odbiorcy, zgodnie z argumentacją skarżącej, będą uznawać butelkę bez żłobień za ewolucję butelki ze żłobieniami. OHIM, wydając wobec Coca-Cola Company decyzję odmowną, uznał, że nie można uznać argumentu spółki, że „wspomniani odbiorcy dostrzegą bezpośrednio i natychmiast związek między

\footnotetext{
${ }^{25}$ Pkt 8 wyroku w sprawie The Coca-Cola Company.

${ }^{26}$ Pkt 12 wyroku w sprawie The Coca-Cola Company.
} 
tym oznaczeniem a butelką konturową ze żłobieniami, z której skarżąca jest znana na całym świecie" ${ }^{27}$. Do argumentacji OHIM przychylił się również Sąd w rozpatrywanej sprawie. Skład orzekający zwrócił uwagę na argumentację spółki, której zdaniem większość butelek napojów jest produkowana w taki sposób, aby przyciągać uwagę konsumentów ${ }^{28}$. Sąd zauważył jednak, że przeciętny konsument kojarzy przede wszystkim zazwyczaj znak słowny lub graficzny, a skojarzenie ze znakiem trójwymiarowym nie jest już tak powszechne ${ }^{29}$. Co prawda Coca-Cola uznała, że zgłoszony znak towarowy „był wykorzystywany przez osoby trzecie w różnych formach wyrazu kulturowego" i tym samym ma charakter wyróżniający ${ }^{30}$, w badaniu rynku przedstawionym przez spółkę wykazano jednak, że znak towarowy uzyskał charakter wyróżniający jedynie w 10 państwach członkowskich (na 27 państw członkowskich UE w momencie zgłaszania) ${ }^{31}$.

W postępowaniu zostały zbadane również dowody przedstawione przez spółkę dotyczące wykorzystywania znaku towarowego w ramach pop-art, w publikacjach oraz w mediach. W ocenie Sądu te dane nie dotyczyły butelki bez żłobień, a kultowej butelki ze żłobieniami. Co więcej, większość przedstawionych materiałów pochodziła ze Stanów Zjednoczonych. Nie powinno to budzić zdziwienia, ponieważ nurt pop-artu narodził się w USA. Wśród najbardziej znanych przedstawień coca-coli w nurcie pop-art należy wymienić choćby pracę Andiego Warhola z 1962 r. „Zielone butelki coca coli" (Green Coca-Cola Bottles), wystawianą obecnie w Whitney Museum of American $\mathrm{Art}^{32}$. Sama spółka na swoich stronach internetowych pisze

${ }^{27}$ Pkt 13 wyroku w sprawie The Coca-Cola Company.

${ }^{28}$ Pkt 28 wyroku w sprawie The Coca-Cola Company.

${ }^{29}$ Pkt 37 wyroku w sprawie The Coca-Cola Company. W pkt 55 omawianego wyroku sąd zauważył również, że ,użytkownik końcowy będzie ogólnie zwracał większą uwagę na etykietę towaru lub na jego opakowanie oraz na nazwę, obraz lub rysunek, który na nich widnieje, niż na projekt samego opakowania, to krytyka ta, sama w sobie, tak czy inaczej nie jest w stanie podważyć zasadności oceny dokonanej przez Izbę Odwoławczą".

${ }^{30}$ Pkt 62 wyroku w sprawie Coca-Cola Company. Jednym z argumentów spółki Coca-Cola na poparcie tej tezy było wykorzystanie przez artystów w ich pracach zgłoszonego znaku towarowego. Sąd odniósł się do kwestii uzyskania charakteru odróżniającego jako części butelki konturowej ze żłobieniami (pkt 62, 63 i 64 wyroku) zbiorczo w pkt 88 wyroku uznając, że na podstawie przedstawionych ,dowodów trudno jest [...] ustalić, czy ukazana w nich butelka stanowi przedstawienie butelki konturowej ze żłobieniami, czy też jest to zgłoszony znak towarowy."

${ }^{31}$ Pkt 64 wyroku w sprawie The Coca - Cola Company; Zgodnie z pkt 80 wyroku poziom rozpoznawalności w wybranych państwach członkowskich wynosił od 48\% (Polska) do 79\% (Hiszpania).

${ }^{32}$ https://whitney.org/collection/works/3253 [dostęp: 13.07.2020]. 
o znanych artystach, którzy współpracowali przy przygotowywaniu reklam napoju ${ }^{33}$. Tym samym symbolem popkultury jest butelka konturowa ze żłobieniami, przedstawiana m.in. w pracach Burtona, która kojarzy się konsumentom na całym świecie $\mathrm{z}$ flagowym produktem spółki Coca-Cola, natomiast jej uproszczona wersja bez żłobień nie zasługuje, w ocenie Sądu, na ochronę, gdyż nie jest znakiem powszechnie rozpoznawanym. Nie wyklucza to oczywiście możliwości włączenia dyskutowanego znaku towarowego w nurt popkulturowy i tym samym w konsekwencji przyszłego uzyskania przez niego charakteru odróżniającego.

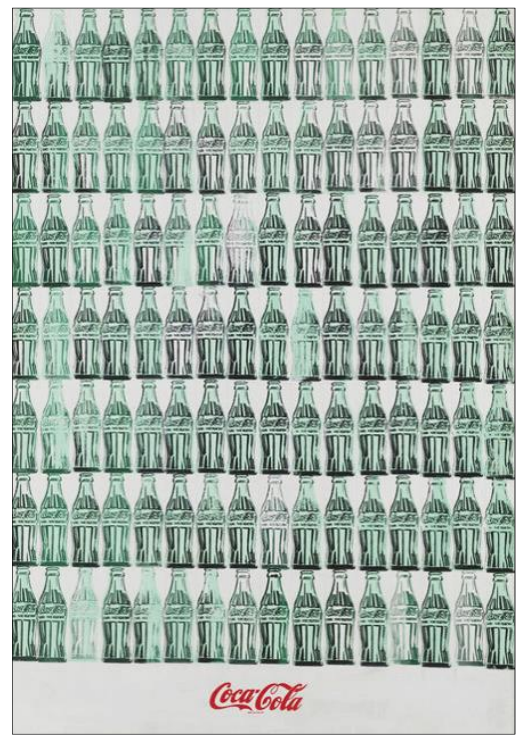

Andy Warhol, Green Coca-cola bottles, 1962 Źródło: www.artsy.net, dostęp 13.07.2020.

W niniejszym artykule, traktującym o zjawisku „makdonaldyzacji” kultury w orzecznictwie TSUE, nie może zabraknąć również ikony popkultury, jaką jest McDonald's. Złote łuki (,golden arches”) składające się w literę „M” od McDonald's są dziś jednym z najbardziej rozpoznawalnych logo na świecie. Dla polskich konsumentów, dosłownie spragnionych tego, jak smakuje „Zachód”, dzień 17 czerwca 1992 r. zapisał się podwójnie - jako ten, w którym otwarto w Warszawie pierwszą w Polsce restaurację McDonald's,

33 „Famous Artists Who Have Worked With Coca-Cola”. 13.07.2020. The Coca-Cola Company, dostęp 13.07.2020, https://www.coca-colacompany.com/news/famous-artists-who-have-workedwith-coca-cola. 
oraz dzień, w którym ustanowiono rekord świata dla tej sieci fast-foodów w liczbie transakcji w dniu otwarcia, wynoszącą $13304^{34}$. Dwa lata później na ekranach kin pojawił się film Quentina Tarantino Pulp Fiction, w którym bohaterowie Jules i Vincent prowadzą jeden z częściej cytowanych dialogów $\mathrm{z}$ tego filmu o różnicach $\mathrm{w}$ nazewnictwie kanapek $\mathrm{w}$ restauracjach McDonald's w USA i Paryżu, spowodowanych dwoma różnymi systemami metrycznymi, przy czym na kanapkę Big Mac Francuzi mówią Le Big Mac ${ }^{35}$. Do konfliktu interesów dotyczącego tej marki doszło przy okazji sprawy Future Enterprises Pte Ltd przeciwko EUIPO, w której drugą stroną przed Izbą Odwoławczą EUIPO była występująca przed Sądem w charakterze interwenienta McDonald's International Property Co. Ltd (dalej jako sprawa McDonald's) ${ }^{36}$. Podłożem sprawy było unieważnienie w 2012 r. przez Wydział Unieważnień na wniosek McDonald's znaku towarowego, należącego do spółki Future Enterprises, stanowiącego oznaczenie słowne MACCOFFEE. Wniosek o unieważnienie znaku MACCOFFEE McDonald's uzasadniał wcześniejszymi rejestracjami unijnych (poza wyjątkiem dotyczącym znaku niemieckiego McDonald's) znaków towarowych m.in. MCDONALD'S, McFISH, McMUFFIN, McCHICKEN ${ }^{37}$, które łączył wspólny przedrostek „Mc”. Co istotne, swoją decyzję unieważniającą znak towarowy MACCOFFEE Wydział Unieważnień oparł wyłącznie na wcześniejszym unijnym znaku towarowym - McDONALD'S, uznając, że wieloletnia nabyta przezeń renoma oraz odczucie związku między tym znakiem a znakiem spornym u zainteresowanych odbiorców są tak silne, iż w przypadku nieuzasadnionego używania znaku MACCOFFEE spowoduje to czerpanie nienależnej korzyści $z$ renomy znaku towarowego McDONALD' ${ }^{38}$. Naruszenie polegające , ,[...] na czerpaniu nienależnej korzyści z charakteru odróżniającego lub renomy wcześniejszego znaku towarowego - w zakresie, w jakim zakazane jest czerpanie korzyści z tego znaku przez właściciela późniejszego znaku towarowego - winno być oceniane w odniesieniu do sposobu rozumowania przeciętnego, właściwie poinformowanego, dostatecznie uważnego i rozsądnego konsumenta towarów lub usług, dla których został zarejestrowany późniejszy

\footnotetext{
34 „Historia McDonald's”. MCDONALDS.PL, dostęp 17.07.2020. https://mcdonalds.pl/o-mcdonalds/ kim-jestesmy/historia/.

${ }^{35}$ Film Pulp Fiction, 1994. FILMweB. Dostęp 17.07.2020. https://www.filmweb.pl/film/Pulp+ Fiction-1994-1039

${ }^{36}$ Wyrok Sądu z 5.07.2016 r. w sprawie Future Enterprises Pte Ltd przeciwko Urzędowi Unii Europejskiej ds. Własności Intelektualnej, T 518/13, ECLI:EU:T:2016:389.

${ }^{37}$ Pkt 6 wyroku w sprawie McDonald's.

${ }^{38}$ Pkt 9 wyroku w sprawie McDonald's.
} 
znak towarowy"39. Wzorzec europejskiego konsumenta, który jest właściwie poinformowany, dostatecznie uważny i rozsądny, ukształtowany $\mathrm{w}$ sprawie C-470/93 ${ }^{40}$, służy w tym przypadku do mierzenia rozpoznawalności znaku towarowego.

Pierwsza Izba Odwoławcza doszła do podobnych wniosków, m.in. uznając, że obydwa znaki są podobne, a renoma znaku towarowego McDONALD'S, nabyta przez lata jego funkcjonowania w świadomości swoich odbiorców, rozciąga się również na połączenie przedrostka „Mc” z nazwą pozycji menu lub produktu żywnościowego, nazywając takie połączenie rodziną znaków towarowych „Mc”,

W wyniku zaskarżenia decyzji Pierwszej Izby Odwoławczej EUIPO, oddalającej odwołanie Future Enterprises od decyzji Wydziału Unieważnień, sprawa trafiła na wokandę Sądu. Skarżąca spółka kwestionowała m.in. ustalenia Izby Odwoławczej co do istniejącego między znakami towarowymi pewnego poziomu podobieństwa, twierdząc, że różnią się one wizualnie, fonetycznie oraz pod względem konceptualnym ${ }^{42}$. Sąd przychylił się jedynie do pierwszego zarzutu, uznając, że ,[...] błędny jest wniosek, zgodnie z którym kolidujące ze sobą znaki towarowe są wizualnie podobne w niewielkim stopniu [...]" "43. Pod uwagę brano poszczególne litery w oznaczeniach stanowiących znaki towarowe, a tutaj faktycznie zbieżność występuje tylko w przypadku liter „m”, „c”, „o” i „a”, przy tym jedynie litera „m” występuje $\mathrm{w}$ znakach na tej samej pozycji - pierwszej ${ }^{44}$. W przypadku podobieństwa

\footnotetext{
${ }^{39}$ Pkt 93 wyroku w sprawie McDonald's.

${ }^{40}$ Wyrok Trybunału Sprawiedliwości z 6.07.1995 r. w sprawie C-470/93, Verein gegen Unwesen in Handel und Gewerbe Köln e.V. przeciwko Mars GmbH, ECLI:EU:C:1995:224.

${ }^{41}$ Pkt 11 wyroku w sprawie McDonald's: „W swoich rozważaniach Sąd potwierdził znaczenie istnienia rodziny znaków towarowych 'Mc'. Sąd konkludował, że znaki towarowe McMUFFIN, McRIB, McFLURRY, CHICKEN McNUGGETS, McCHICKEN i EGG McMUFFIN wywodzą się ze znaku towarowego McDONALD'S i odtwarzają w całości ten sam element odróżniający 'mc', a więc spełniają przesłanki warunkujące powstanie 'rodziny' znaków towarowych, także w sytuacji, gdy drugi element znaku McDONALD'S odnosi się do nazwiska patronimicznego, natomiast $\mathrm{w}$ pozostałych znakach tworzących rodzinę znaków odnosi się on do nazwy produktu. Pierwotnym znakiem towarowym rodziny jest powszechne znane oznaczenie McDONALD'S, od którego pochodzą wszystkie znaki pochodne posiadające wspólny przedrostek 'mc' i różniące się elementem końcowym, który jest jednak tego samego rodzaju, gdyż stanowi produkt żywnościowy widniejący w menu barów szybkiej obsługi (pkt 64 wyroku)". Karolina Sztobryn, „O wzmożonej ochronie McZnaków”, Glosa - Prawo Gospodarcze w orzeczeniach i komentarzach 2017, $\mathrm{nr} 3,:$ 78-87.

${ }^{42}$ Pkt 18 wyroku w sprawie McDonald's.

${ }^{43}$ Pkt 25 wyroku w sprawie McDonald's.

${ }^{44}$ Pkt 24 wyroku w sprawie McDonald's.
} 
fonetycznego oraz konceptualnego skład orzekający potwierdził ustalenia Izby Odwoławczej, uznając brzmienie początkowej części tych znaków - przedrostka „mac” oraz „mc” — za fonetycznie podobne ${ }^{45}$, jak i związane z tą samą ideą $-\mathrm{z}$ przedrostkiem goidelskich nazwisk patronimicznych ${ }^{46}$. W rezultacie całościowego podobieństwa, mimo mylnego ustalenia Izby Odwoławczej co do podobieństwa wizualnego znaków, zarzuty skarżącej oddalono.

W sprawie Simba Toys GmbH \& Co. KG przeciwko EUIPO ${ }^{47}$ (dalej jako sprawa Simba Toys) interwenientem w pierwszej instancji był Seven Towns Ltd, producent „kostki Rubika”. W 1996 r. Seven Towns dokonał zgłoszenia wspólnotowego znaku towarowego - kształtu sześcianu o powierzchniach mających strukturę siatki. Uzyskał rejestrację jako wspólnotowy znak towarowy w 1999 r. Rejestrację tego znaku przedłużono 10 listopada 2006 r., a 15 listopada 2006 r. Simba Toys wniosła o jej unieważnienie, lecz wniosek został oddalony przez Wydział Unieważnień EUIPO. Izba Odwoławcza utrzymała w mocy decyzję Wydziału Unieważnień, co do której Simba Toys wniosła do EUIPO o jej odwołanie. W postępowaniu przed Sądem, na skutek wniesienia przez Simba Toys skargi o nieważność decyzji, Sąd w wyroku oddalił tę skargę jako bezzasadną. Ostatecznie Trybunał uchylił wyrok Sądu Unii Europejskiej oraz stwierdził nieważność decyzji Izby Odwoławczej, przychylając się tym samym do argumentacji przedstawionej przez Simba Toys, koncentrującej się na art. 7 rozporządzenia $\mathrm{nr} 40 / 94^{48}$, zatytułowanym „Bezwzględne podstawy odmowy rejestracji”, którego ust. 1 lit e) ppkt (ii) stanowi, że nie są rejestrowane „,[...] oznaczenia, które składają się wyłącznie z: [...] kształtu towaru niezbędnego do uzyskania efektu technicznego [...]”. Zarejestrowanie przez Seven Towns oznaczenia w postaci „kształtu sześcianu o powierzchniach mających strukturę siatki" ${ }^{49}$, zdaniem Simba Toys, naruszało powyższy przepis, gdyż ,[...] czarne linie, i ogólniej ukazana na każdej z powierzchni spornego sześcianu struktura siatki, spełniają funkcję techniczną"50. W ocenie Trybunału art. 7 ust. 1 lit. e) ppkt (ii) ,[...] dotyczy jedynie oznaczeń tworzonych przez kształt konkretnego towaru,

\footnotetext{
${ }^{45}$ Pkt 28 wyroku w sprawie McDonald's.

${ }^{46}$ Pkt 31 wyroku w sprawie McDonald's.

${ }^{47}$ Wyrok Trybunału Sprawiedliwości z 10.11.2016 r. w sprawie Simba Toys GmbH \& Co. KG przeciwko Urzędowi Unii Europejskiej ds. Własności Intelektualnej (EUIPO), C 30/15 P, ECLI:EU:C:2016:849.

${ }^{48}$ Rozporządzenie Rady (WE) nr 40/94 z dnia 20 grudnia 1993 r. w sprawie wspólnotowego znaku towarowego (Dz.U. 1994, L 112, 1).

${ }^{49}$ Pkt 1 wyroku w sprawie Simba Toys.

${ }^{50}$ Pkt 42 wyroku w sprawie Simba Toys.
} 
oceny zasadniczych właściwości kształtu należy dokonywać w świetle funkcji technicznej rozpatrywanego konkretnego towaru [... "ग51 i celem tego przepisu jest, ,[...] zapobieganie temu, aby prawo znaków towarowych prowadziło do przyznania jednemu przedsiębiorstwu monopolu na rozwiązania techniczne lub na cechy użytkowe danego towaru [... $]^{152}$. Sporne „[...] oznaczenie jest tworzone przez kształt konkretnego towaru, a nie kształt abstrakcyjny [...]" ${ }^{, 53}$. Konkretnym towarem jest w tym przypadku zabawka kostka Rubika, posiadająca zdolność rotacji.

Art. 7 ust. 1 lit. e) ppkt (ii) rozporządzenia nr 40/94 stał się również podstawą wniesienia wniosku o unieważnienie innego znaku towarowego, dotyczącego popkulturowej marki i znanego na całym świecie „ludzika” LEGO. W sprawie Best-Lock (Europe) Ltd przeciwko EUIPO ${ }^{54}$, w której interwenientem w pierwszej instancji była spółka LEGO Juris A/S (dalej jako sprawa Best-Lock) Best-Lock, który produkował figurki podobne do figurek LEGO, postanowił zakwestionować rejestrację znaku towarowego w postaci oznaczenia trójwymiarowej figurki. W tym jednak wypadku żadna $\mathrm{z}$ instancji nie doszukała się podstawy unieważnienia znaku towarowego. Argument, że oznaczenie w postaci trójwymiarowej figurki składa się wyłącznie z kształtu towaru niezbędnego do uzyskania efektu technicznego, czyli możliwości łączenia z innymi klockami LEGO, okazał się niewystarczający. Trybunał potwierdził, że aspekt techniczny, czyli otwory w stopach i z tyłu nóg figurki, mogą co prawda służyć łączeniu jej z innymi elementami LEGO, nie stanowią jednak elementu niezbędnej charakterystyki kształtu, jaką jest przedstawienie figurki w ludzkiej formie ${ }^{55}$. Orzeczenie Trybunału, zwracające uwagę na to, że figurka przede wszystkim ma przypominać ludzką formę, a dopiero w dalszej kolejności pozwalać na łączenie z innymi elementami, wydaje się o tyle trafne, że figurki LEGO już dawno połączyły siły z przemysłem kinowym i gier wideo i wcieliły się w role m.in. Batmana czy bohaterów trylogii Władca Pierścieni ${ }^{56}$.

\footnotetext{
${ }^{51}$ Pkt 46 wyroku w sprawie Simba Toys.

${ }^{52}$ Pkt 39 wyroku w sprawie Simba Toys.

${ }^{53}$ Pkt 47 wyroku w sprawie Simba Toys.

${ }^{54}$ Wyrok Trybunału Sprawiedliwości z 14.04.2016 r. w sprawie Best-Lock (Europe) Ltd przeciwko Urzędowi Unii Europejskiej ds. Własności Intelektualnej (EUIPO), C-451/15 P, ECLI: EU:C:2016:269.

${ }^{55}$ Pkt 20 wyroku w sprawie Best-Lock.

${ }^{56}$ Film Lego Przygoda. The Lego Movie, 2014. FILMwEB, dostęp 17.07.2020. https:// www. filmweb.pl/film/LEGO\%C2\%AE+PRZYGODA-2014-537050.
} 


\section{KONKLUZJE}

Prezentowany artykuł miał na celu odpowiedzieć na pytanie, czy popkultura ze względu na swoją efemeryczność zasługuje na ochronę prawną i czy ta ochrona jest realna. Autorzy postanowili udzielić odpowiedzi na to pytanie na podstawie aktualnego orzecznictwa TSUE, w którym od kilku lat pojawiają się sprawy dotyczące ikon popkultury. Te sprawy, w ocenie autorów, wpisują się w szeroko rozumiany dorobek orzeczniczy dotyczący kultury (tzw. acquis culturalis).

$\mathrm{Na}$ podstawie przeanalizowanych orzeczeń można stwierdzić, że dobra popkultury mogą podlegać realnej ochronie prawnej na podstawie przepisów odnoszących się do ochrony znaków towarowych. Ochrona udzielana produktom kultury masowej poprzez rejestrację znaków towarowych jest możliwa, gdy taki produkt zyskuje charakter wyróżniający go na rynku spośród innych produktów - tym samym coraz większą rolę w kreowaniu popkulturowych ikon odgrywają konsumenci i ich wybory. Ochrona rozpoznawalnych w kulturze masowej „,znaków pop-kulturowych”, jak np. ludzik LEGO, stanowi specyficzny znak czasów oraz przykład powiązania kultury z tzw. sektorami kreatywnymi. W orzecznictwie TSUE początkowo sprawy dotyczące życia kulturalnego były powiązane z problematyką swobody przepływu towarów i usług, aby z czasem zyskać miejsce bardziej niezależne ${ }^{57}$. Analizowane orzeczenia dotyczące ikon popkultury wskazują, że historia niejako zatacza koło, a dobra kultury stają się produktami masowymi w wyniku postmodernistycznych przeobrażeń życia społecznego i kulturalnego.

\section{BIBLIOGRAFIA}

ŹRÓDŁA PRAWA

PRAWO UNII EUROPEJSKIEJ

Traktat o Unii Europejskiej, wersja skonsolidowana. Dz.U. UE C 202 z 7.06.2016, 13.

Rozporządzenie Parlamentu Europejskiego i Rady (UE) 2017/1001 z dnia 14 czerwca 2017 r. w sprawie znaku towarowego Unii Europejskiej. Dz.U. UE L 154 z 16.6.2017, 1.

Rozporządzenie Rady (WE) nr 207/2009 z dnia 26 lutego 2009 r. w sprawie wspólnotowego znaku towarowego. Dz.U. UE L 78 z 24.3.2009, 1.

Rozporządzenie Rady (WE) nr 40/94 z dnia 20 grudnia 1993 r. w sprawie wspólnotowego znaku towarowego, Dz.U. UE z 1994, L 112, 1.

\footnotetext{
${ }^{57}$ Zob. np. Wyrok TSUE z dnia 3 września 2014 r. Johan Deckmyn i Vrijheidsfonds VZW przeciwko Helenie Vandersteen i in., C 201/13, ECLI:EU:C:2014:2132.
} 
PRAWO KRAJOWE

Konstytucja Rzeczypospolitej Polskiej z dnia 2 kwietnia 1997 r. Dz.U. 1997 Nr 78 poz. 483.

Międzynarodowy Pakt Praw Gospodarczych, Społecznych i Kulturalnych otwarty do podpisu w Nowym Jorku dnia 19 grudnia 1966 r. Dz.U. z 1977 r. Nr 38 poz. 169.

\section{ORZECZNICTWO}

Wyrok Trybunału Sprawiedliwości z 10.11.2016 r. w sprawie Vereniging Openbare Bibliotheken przeciwko Stichting Leenrecht. C 174/15, ECLI:EU:C:2016:856.

Wyrok Trybunału Sprawiedliwości z 10.11.2016 r. w sprawie Simba Toys GmbH \& Co. KG przeciwko Urzędowi Unii Europejskiej ds. Własności Intelektualnej (EUIPO). C 30/15 P, ECLI:EU:C:2016:849.

Wyrok Sądu z 5.07.2016 r. w sprawie Future Enterprises Pte Ltd przeciwko Urzędowi Unii Europejskiej ds. Własności Intelektualnej. T 518/13, ECLI:EU:T:2016:389.

Wyrok Trybunału Sprawiedliwości z 2.06.2016 r. w sprawie Nabiel Peter Bogendorff von Wolffersdorff przeciwko Standesamt der Stadt Karlsruhe i Zentraler Juristischer Dienst der Stadt Karlsruhe. C 438/14, ECLI:EU:C:2016:401

Wyrok Trybunału Sprawiedliwości z 14.04.2016 r. w sprawie Best-Lock (Europe) Ltd przeciwko Urzędowi Unii Europejskiej ds. Własności Intelektualnej (EUIPO). C-451/15 P, ECLI: EU:C:2016:269.

Wyrok Sądu z dnia 24 lutego 2016 r. The Coca-Cola Company przeciwko Urzędowi Harmonizacji w ramach Rynku Wewnętrznego. T 411/14, ECLI:EU:T:2016:94.

Wyrok TSUE z dnia 3 września 2014 r. Johan Deckmyn i Vrijheidsfonds VZW przeciwko Helenie Vandersteen i in. C 201/13, ECLI:EU:C:2014:2132.

Wyrok Trybunału Sprawiedliwości z 22.12.2010 r. w sprawie Ilonka Sayn-Wittgenstein przeciwko Landeshauptmann von Wien. C 208/09, ECLI:EU:C:2010:806.

Wyrok Trybunału Sprawiedliwości z 30.04.2009 r. w sprawie Fachverband der Buch- und Medienwirtschaft przeciwko LIBRO Handelsgesellschaft mbH, C 531/07, ECLI:EU:C:2009:276.

Wyrok Trybunału Sprawiedliwości z 16.01.2003 r. w sprawie Komisja Wspólnot Europejskich przeciwko Republice Włoskiej. C 388/01, ECLI:EU:C:2003:30.

Wyrok Trybunału Sprawiedliwości z 8.07.1999 r. w sprawie Teresa Fernández de Bobadilla przeciwko Museo Nacional del Prado, Comité de Empresa del Museo Nacional del Prado i Ministerio Fiscal. C 234/97, ECLI:EU:C:1999:367.

Wyrok Trybunału Sprawiedliwości z 25.07.1991 r. w sprawie Stichting Collectieve Antennevoorziening Gouda i inni przeciwko Commissariaat voor de Media. C 288/89, ECLI:EU: C:1991:323.

\section{OPRACOWANIA}

Bauman, Zygmunt. Szkice z teorii kultury. Warszawa: Wydawnictwo Naukowe Scholar, 2017.

Kaliszewski, Andrzej. Główne nurty w kulturze XX i XXI wieku. Warszawa: Poltext, 2012.

KŁosкowsкa, Antonina. Kultura masowa. Biblioteka Socjologiczna. Warszawa: Wydawnictwo Naukowe PWN, 2005.

KopAliŃski, Władysław. Słownik mitów i tradycji kultury. Warszawa: Państwowy Instytut Wydawniczy, 1987.

KosińsKA, Anna Magdalena. Kulturalne prawa człowieka. Lublin: Wydawnictwo KUL, 2014. 
KosińsKa, Anna Magdalena. Prawa kulturalne obywateli państw trzecich w prawie Unii Europejskiej. Lublin: Wydawnictwo KUL, 2018.

Sztobryn, Karolina. „O wzmożonej ochronie McZnaków”. Glosa-Prawo Gospodarcze w orzeczeniach i komentarzach" 2017, nr 3: 78.-87.

Warhol, Andy. The Philosophy of Andy Warhol: From A to B and Back Again. New York: Harcourt Brace Jovanovich, 1975.

\section{NetOgRAFia}

EUIPO. The European Union Intellectual Property Office - Urząd Unii Europejskiej ds. Własności Intelektualnej. Dostęp 13.07.2020. https://euipo.europa.eu/ohimportal/pl/the-office.

„Famous Artists Who Have Worked With Coca-Cola”. 13.07.2020. The Coca-Cola Comapany. Dostęp 15.07.2020. https://www.coca-colacompany.com/news/famous-artists-who-have-workedwith-coca-cola.

Film Pulp Fiction, 1994. FILMwEB. Dostęp 17.07.2020. https://www.filmweb.pl/film/Pulp+Fiction1994-1039.

Film Lego Przygoda. The Lego Movie, 2014. FILMwEB. Dostęp 17.07.2020. https://www.filmweb.pl/ film/LEGO\%C2\%AE+PRZYGODA-2014-537050.

„Historia McDonald's”. MCDONALDS.PL. Dostęp 17.07.2020. https://mcdonalds.pl/o-mcdonalds/ kim-jestesmy/historia/.

LEGO. Dostęp 15.07.2020. https://www.lego.com/pl-pl/themes/art.

„'Mean' Joe Green Reflects on Iconic Coca-Cola Ad That Changed His Life: Commercial Appeal". 16.01.2014. The Coca-Cola Comapany. Dostęp 17.07.2020. https://www.coca-cola company.com/news/mean-joe-green-reflects-on-iconic-coke-ad.

„Michael Jackson Pepsi Generation”. SME. Dostęp 17.07.2020. Youtube. https://youtube/po0j Y4WvCIc.

Whitney Museum of American Art. Dostęp 17.07.2020. https://whitney.org/collection/works/3253.

\section{ZJAWISKO „MAKDONALDYZACJI” KULTURY \\ W ORZECZNICTWIE TRYBUNAŁU SPRAWIEDLIWOŚCI UNII EUROPEJSKIEJ}

\section{Streszczenie}

Artykuł analizuje orzecznictwo Trybunału Sprawiedliwości Unii Europejskiej dotyczące szeroko rozumianych ikon popkultury. Takie sprawy pojawiają się od kilku lat na wokandzie TSUE i dotyczą m.in. takich produktów, jak Coca-Cola, LEGO czy kostka Rubika. Artykuł stawia sobie za cel odpowiedź na pytanie, czy popkultura ze względu na swoją efemeryczność zasługuje na ochronę prawną i czy owa ochrona jest realna. Prezentowane orzeczenia są analizowane w świetle prawa Unii Europejskiej na szerokim tle wszechobecnej kultury masowej.

Slowa kluczowe: acquis culturalis; kultura masowa; ochrona dóbr kultury; orzecznictwo TSUE; popkultura. 


\section{MCDONALDIZATION OF THE CULTURE IN THE CASE-LAW OF THE COURT OF JUSTICE OF THE EUROPEAN UNION}

\section{S u m m ary}

The article analyzes the case-law of the Court of Justice of the EU regarding widely understood pop-culture icons. The cases concerning such goods have been present before the cjeu for few years and pertain to products like Coca-Cola, LEGO and Rubic's cube. The article aims to answer the question if the pop-culture, despite of its ephemerality, can be efficiently protected. The presented case-law has been analyzed in the light of the European Union law in the context of the omnipresent mass culture.

Key words: acquis culturalis; CJEU; mass culture; pop culture; protection of the cultural goods. 